\title{
The First Hundred Years: a History of Eye Tracking as a Research Method
}

\author{
Monika PŁUŻYCZKA \\ Uniwersytet Warszawski/ University of Warsaw \\ E-mail: mpluzyczka@uw.edu.pl,
}

\begin{abstract}
The paper describes the first hundred years of the history of eye tracking as a research method, dividing it into three phases of development. It starts by presenting the studies on tracing eye movements in reading in the end of the $19^{\text {th }}$ century and the creation of the first eye trackers. The further part presents how the eye tracking technology was improved in the time of film recordings, ceasing to be invasive for the eyes. It also shows how in this time the main focus of research shifted to practical aspects due to the development of the behaviourist movement in experimental psychology. The third phase starts in the 1970s, when researchers turned more towards the dependence between the perception and mental processes. It was linked to the establishment of a theoretical and methodological basis for cognitive psychology.
\end{abstract}

Keywords: eye tracking, research, history, technology, eye movements, reading process, development, eye trackers

\section{1.}

The technological progress and increasing dissemination of research equipment (such as eye trackers, EEG) in disciplines not related to medicine, as well as more and more easier access to state-of-the-art devices (e.g. fMRI) have opened up new cognitive possibilities to humanities. Linguistics, language didactics and translation studies, too, use increasingly the technological possibilities to extend their boundaries of cognition. One of such technological method in translation studies (in use in this academic discipline for about 12 years) is eye tracking.

Eye tracking devices allow to trace the eye movement, whereas a special software enables to process the data in such a way that it becomes possible to interpret the data scientifically. At the foundation of this kind of research lies the assumption that there is a correlation between eye movements and particular mental processes. The eye, i.e. sight, is for humans one of the most important senses. Nearly $80 \%$ of all sensory impressions are delivered to the brain via the visual channel. Vision provides also information at the highest level of speed. The speed of data transmission is measured in bits per second, various senses transfer information at the following speed: eyes (sight) - provide information at a speed of $10 \mathrm{million} \mathrm{bit} / \mathrm{s}$, skin (touch) - one million bit/s, ears (hearing) - 100,000 bit/s, nose (smell) - 100,000 bit/s, tongue (taste) - $1000 \mathrm{bit} / \mathrm{s}$ (quoted from: V. Gollücke 2009). Moreover, $10 \%$ of the cerebral cortex is involved in the interpretation of visual information. The visual 
cortex, in turn, accounts for about $60 \%$ of the whole cerebral cortex, taking into account all areas responsible for responses to visual stimuli. This means that most of the information (and in the fastest way) man gathers from surrounding world is received by means of sight. Furthermore, visual activity is the easiest one to examine, after verbal and motoric operations, when it comes to the whole range of human behaviour. This is yet another reason for the rising popularity of eye tracking studies.

It should not surprise then that also translation studies attempt to increasingly use the achievements of eye tracking. The use of these achievements in translation studies enables us to collect interesting data on how we perceive visually during translation, and consequently also on how we process information during the translation act and what mental processes are involved in the act.

In this article I will address the history of eye tracking studies, focusing in particular on the area of greatest interest to me, namely on studies regarding text perception.

\section{2.}

Eye tracking seems to be a modern technology, however, its roots can be traced back to the 19th century, when regular studies on the reading process began (G. Bente 2005). At the beginning researchers studied eye movements without measuring equipment, based on normal observations. A mirror was placed on the pages of the book read by the test subject, behind whose back stood the experimenter who observed the movement of the test subject's eyes in that mirror. Of course, that method was far from being precise, nonetheless it yielded some interesting conclusions regarding the visual perception during reading.

As to who was first to conduct studies on tracking eye movement during reading, there is some inaccuracy. Most sources report that the first researcher to have described the movement of the eyes during reading was French ophthalmologist Louis Émile Javal, at the end of the 1870s and these years are also considered the beginning of the era of eye tracking studies. The scientific experiments led L.É. Javal to the conclusion in 1879 that reading did not require eyes to move continuously along a line of text, as had been assumed previously. He proceeded to explain that reading was not a linear process, meaning that the test subject's eyes did not move continuously during the passage over each line but that it is more a process consisting in short rapid movements (saccades) intermingled with pauses, or short stops of the eyes (fixations) on concrete elements.

In the article "Did Javal Measure Eye Movements during Reading?" (2009) N.J. Wade and B. W. Tatler challenged the proposition that it had been L.É. Javal who was the first to carry out and describe such tests. They determined - and it seems they were right in doing so - that L.É. Javal had been attributed the achievements of M. Lamare' ${ }^{1}$. This mistake was due to the misinterpretation of words of E.B. Huey

\footnotetext{
${ }^{1}$ As stressed by the authors, in those times many undertook to study eye movements, including such scholars as: E. Rählmann (1878), A. Ahrens (1891), E. Landolt (1891), M.H.E.
} 
who had written:

Lamare, working with Javal, finding that the movement of the eye in reading was not continuous, but by little jerks (par saccades), devised the following method for counting these: A blunt point placed on the upper eyelid of the reader put in action a microphone, whose sound, transmitted by a rubber tube, made known each movement to the ear of the experimenter the short reading jerks causing a brief sound, while the extensive movements made in passing from the end of the line to the commencement of the next, caused a more prolonged sound (E.B. Huey 1900: 285).

The authors of the article stress that he really meant the research of M. Lamare who had been conducting studies in L.É. Javal's laboratory. These experiments were actually described by L.É. Javal himself:

Following the research of M. Lamare in our laboratory, the eye makes several saccades during the passage over each line, about one for every 15-18 letters of text. It is probable that in myopes the eye reacts with a rapid change in accommodation with every one of these saccades (L.É. Javal 1879: 252).

The supposition of the authors is confirmed by L.E. Javal's own words as he always stressed in his works that it was M. Lamare who carried out the studies that indicated that the eye movement in the reading process was not linear (see also: L.É. Javal 1905: 127).

L.É. Javal, in turn, wrote on the basis of his observations that he did not notice vertical eye movements during reading, and this argument actually stands in contrast to words attributed to him:

(...) gaze glides along a line slightly higher than the centre of the characters. The reason for this is easy to see: if gaze simply glides horizontally, complicated and useless movements are avoided, and the chosen position of the horizontal is determined by the structure of the typographic characters ${ }^{2}$ (L.É. Javal 1878: 251).

Doubtlessly, L.É. Javal's contribution was the first-time use of the term "saccades". L.É. Javal counted those saccades by attaching a microphone to the upper eyelid of the reader. When the reader's gaze slid along the text, it was possible to record the eye movement next to the microphone (J. Grobelny et al. 2006).

Little is known about M. Lamare besides the above-mentioned citations. He failed to publish anything for over a decade after carrying out his experiments. He later described several methods he had been using in order to count and analyse saccades during reading. However, as he was not satisfied with his observations of eye movements, he created a device that would be able to record the eye jerks and stops. He placed a blunt point on the eyelid; that point "captured" the sound created by each saccade, transferring it as a soft snap to the experimenter's ear, via a drum with an ebonite membrane in the centre and to which a small tube was attached:

Tscherning (1898). A. Ahrens attempted to examine the eye movements using a lens made of ivory and hair attached to it. While he was not able to go through with his idea, it was later used by E. B. Delabarre (1898) and E. B. Huey $(1898,1900)$. 
The method that gives the best results is one by which the movements are heard via a drum with an ebonite membrane in the centre and to which a small tube is attached; the tube is in contact with the conjunctiva or eyelid and is connected to both ears by rubber tubes... The apparatus yields distinctive sounds which an assistant can count and add, and note for each line. The return movement of the eyes to the beginning of a line gives a longer and louder noise that is easy to recognise; one counts the number of saccades from the start of the line to be able to note the number of divisions that occur in a line (M. Lamare 1892: 357; italic print by the author).

M. Lamare was the first to apply a mechanical device, arguing that saccades were easier to register by sound than by sight, which now seems quite a surprising assertion.

A regular examination of eye movements was commenced by E. Huey (1898). $\mathrm{He}$, too, is considered the creator of the first eye tracker. E. Huey used a sort of contact lens with an opening for the iris. That lens was connected with an aluminium indicator which showed the eye movement (regression factor). This method, however, was so invasive to the eye that E. Huey resorted to giving his test subjects cocaine in order to reduce their discomfort during the experiment.

Around the same time (1898) a similarly invasive mechanical method to study eye movements has been worked out by E.B. Delabarre. He used a cap made of gypsum which adhered to the moist surface of the eye. Attached to this cap was a wire that led to a lever which drew horizontal movements of the eye on the sooted surface of a cinematographic cylinder. The test subject (usually E.B. Delabarre himself) was able to read a text through a hole made in the gypsum cap. The eye was anaesthetised with cocaine. The gypsum cap did not detach from the eye until it started filling with tears. It should be noted that E.B. Delabarre himself was unable to determine whether the method was safe for the eye. He merely asserted that after recording eye movements for over an hour, he recover within a week.

The first non-invasive and precise eye tracker, in turn, was created in 1901 by Americans R. Dodge and T.S. Cline who had started the phase of optical eye trackers. They were the first to use light that reflects from the surface of the cornea and falls through an optical system onto a moving photosensitive photographic plate, thus leaving a record of the eye movement on that plate. Their device, called "The Dodge Photochronograph" (it was used mostly by R. Dodge and his collaborators), was a breakthrough in the development of eye tracking technology and it made devices using the reflection of light from the cornea popular. However, R. Dodge's and T.S. Cline's device had two drawbacks: firstly, it registered only horizontal movements of the eyes and it required test subjects to keep their heads still. Nonetheless, thanks to these studies it was discovered that a person does not receive information from the surrounding world at the same time as saccadic movements occur. 


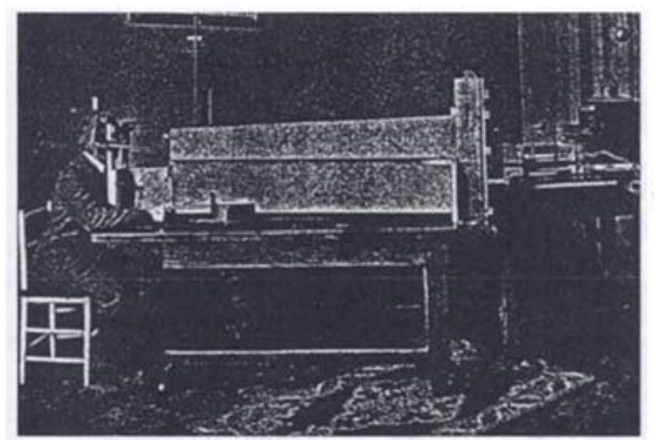

Photograph 1. R. Dodge next to the eye tracker designed by him (A.R. Diefendor/R. Dodge 1908: 462).

The photographic plates used by R. Dodge and T.S. Cline were next replaced by photographic tape.

The next breakthrough in eye tracking research came about with the construction of a device that was able to record both horizontal and vertical eye movements. It was presented a few years later, in 1905, by Ch.H. Judd, C.N. McAlister and W.M. Steel. They placed a small mechanical indicator on the test subject's eye which reflected a light spot. Depending on the position of the eye the light spot depicted the eye movements on a photosensitive tape. The advantage of that method was that there was no mechanical contact with the eye, but it had one drawback, just like the apparatus of R. Dodge and T.S. Cline, i.e. it required the test subject's head to remain still for the device to register changes.

The initial era of eye tracking research yielded results which laid the foundations for subsequent decades of studies and which created a data base on eye movement, perception, seeing and looking. At the heart of research at that time were such issues as saccadic suppression (meaning that we do not receive information during a saccade), the saccade latency (i.e. the time we need to initiate eye movement) and the vision span (i.e. the effective visual field) (see K. Rayner 1998).

The second era of eye movement research started with the time of film recordings in the 1920s. It initiated the development of eye tracking techniques. The new methods had one huge advantage, namely they did not necessitate invasive techniques affecting the test subject, they recorded both directions of eye movement and they provided an objective record of eye movements. However, in terms of experimental precision of the studies, this technique hardly differed from the original observation method.

Meanwhile, electric eye tracking technology was developing at the same time as the above methods. That technology was based on the occurrence of a difference of potentials between the back and the front part of the eye, resulting from the electric activity of the retina. In this method electrodes are placed next to the eye, usually on both sides, to enable the registration of changes of the potential as a result of eye movement (J. Grobelny et al. 2006). In 1922 E. Schott (1922) used the electrooculography which involves counting the varying values of electric potentials of the 
cornea and the retina. The use of this research method considerably improved the accuracy and credibility of results.

The second stage of eye tracking studies was the resultant of technological progress and the development of the behaviourist movement in experimental psychology. Consequently, at that time research on the eye movement focused usually on the practical aspect, that is the specifics of eye movement. Only a small part of that research was devoted to cognitive processes which these movements could have been indicative of:

Psychologists who studied eye movements and fixations prior to the 1970s generally attempted to avoid cognitive factors such as learning, memory, workload, and deployment of attention. Instead their focus was on relationships between eye movements and simple visual stimulus properties such as target movement, contrast, and location. Their solution to the problem of higher-level cognitive factors had been "to ignore, minimize or postpone their consideration in an attempt to develop models of the supposedly simpler lower-level processes, namely, sensorimotor relationships and their underlying physiology" (E. Kowler 1990: 1, quote from: R.J.K. Jacob/ K.S. Karn 2003: 575).

Important publications of the time on reading included: M.A. Tinker $(1946,1958)$, R.Y. Walker (1933), L.G. Stone (1941) and also studies of G.T. Buswell (1935, 1937). In 1930 Miles Tinker and his collaborators began using photographic techniques to study eye movement of readers. He also examined the impact of the font type and size as well as the look and page layout on the outcome and the reading speed as well as their influence on how eye balls move. In turn, G.T. Buswell (1935, 1937) created the first non-contact device registering eye movements. He used it to study the reading and watching of images.
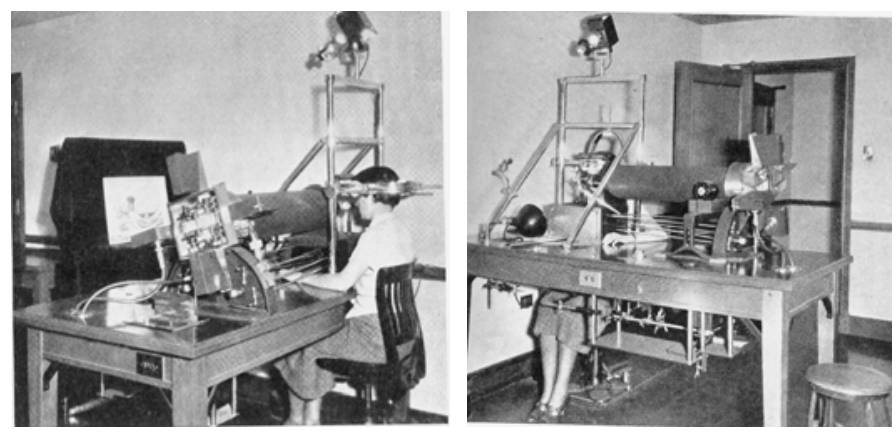

Photograph 2 and photograph 3. Apparatus used for photographing eye movements (G.T. Buswell 1935: 12,13).

Buswell's technique involved a method of separating light reflected from the cornea, which enabled a two-dimensional registration of movements of a single eye: 


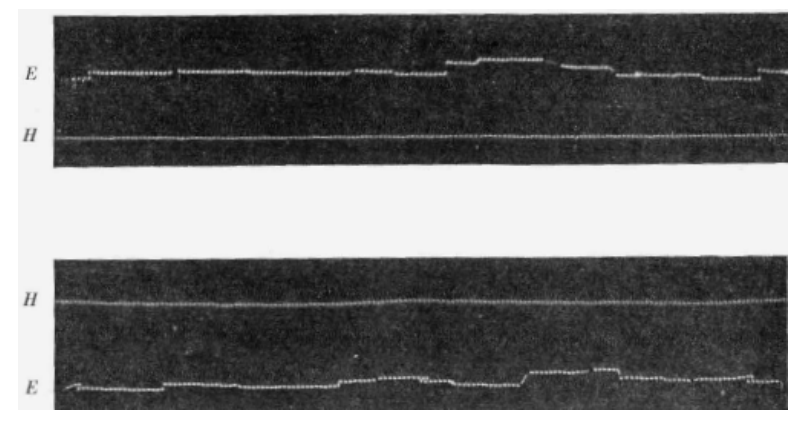

Photograph 4. Sample of film record by eye movement apparatus (G.T. Buswell 1935: 14)3.

The method consisted in photographing on a moving film the eye movements of a group of test subjects while they looked at series of pictures:

The apparatus was built for the particular purpose of this experiment in the workshop of the laboratories in educational psychology of the University of Chicago. Basically the apparatus is a large camera built in such a way that the two films can be moved continuously during the process of photographing. The various lenses and mirrors are simply for the purpose of bringing to a focus on the film the reflection of the tiny spot of light from the cornea of the eye. The light which reflects on the eye originates under the table. It is passed forward through a series of lenses and then upward through two holes in the table, after which it strikes two circular mirrors and is reflected to the subject's eyes. Instead of facing the camera lens, as has been necessary with previous pieces of apparatus of this sort, the subject is placed at right angles to the camera which gives him an open field of vision of whatever size is needed. Small pictures can be placed as close as the normal reading distance of twelve inches, whereas larger pictures can be set back whatever number of feet seems desirable. The provision of this larger field of vision adds a great deal of flexibility to the uses of the apparatus (G.T. Buswell 1935: 11).

Next, in 1947, P.M. Fitts and his collaborators started using a film camera to carry out eye tracking experiments (see P.M. Fitts/ R.E. Jones/ J.L. Milton 1950) in studies on the movement of eyes of pilots using controls in a cockpit and the instrument landing system.

Test subjects were released from immobilisation during tests only in 1948, by H. Hartridge and L.C. Thompson. They created a device that was put on the head of the test participant:

A new type of apparatus has recently been devised by Hartridge and Thomson, namely to hang from a suitable counterpoise a frame which carries the microscope, the reference lights and the corneal light source. It also carries a mouth plate which fits on to the teeth of the subject. The counterpoise is so arranged that the apparatus tends neither to rise nor to fall, but can be freely rotated in all directions. The optical apparatus is so disposed that the subject can observe uninterruptedly suitable fixation points of light which are at-

${ }^{3}$ The upper record shows the horizontal movements of the eye and the lower one shows the vertical movements. The line marked $\mathrm{E}$ indicates eye movements and $\mathrm{H}$ presents record of head movements (G.T. Buswell 1935: 14). 
tached to a wall beyond the apparatus retains the advantage of the previous one, of enabling measurements of eye movements to be obtained which are quite independent of head movements (H. Hartridge and L.C. Thompson, 1948: 588-589).

It was hardly a comfortable method for the test subject, however, it no longer required him to sit still in one place.

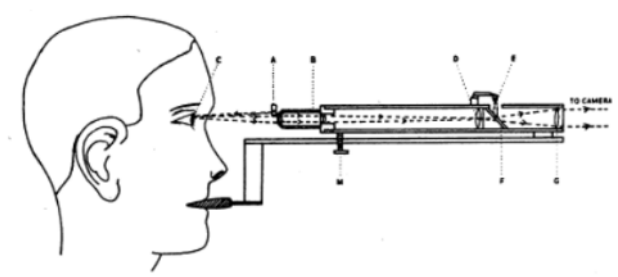

Schema 1. An eye tracker devised by H. Hartridge and L.C. Thompson (H. Hartridge/ L.C. Thompson 1948: 588).

A breakthrough in terms of comfort for subjects was achieved following the development of mobile eye tracker technology. The technology was perfected in the 1960s, by B. Shackel (1960) and N.H. Mackworth and E.L. Thomas (1962), to make them even less burdensome for the test subjects.

Suggested in 1958 by J.F. Mackworth and N.H. Mackworth, the method for registering eye positions in recordings of a scene watched by a test subject during the study represented another important discovery. Thanks to this innovation it became possible to observe eye movement concurrently with the result of that movement, in the form of gazing path of a given element. This eased the interpretation of eye tracking research considerably and it widened research possibilities.

Also, the 1960s brought about a return to the invasive methods of E. Huey and E.B. Delabarre. Scientists of the time came to the conclusion that a cap made of gypsum placed on the eye may be attached to the eye by way of suction. Research of Soviet biophysicist A. L. Yarbus ${ }^{4}$ garnered a lot of attention back then. He studied the movement of eyes using a specific device: a rubber suction cap with a mirror (later replaced with a radio antenna), attached by suction directly to the sclera of the human eye.

${ }^{4}$ A.L. Yarbus = Альфред Лукьянович Ярбус - this transcribed form of the Russian scientist's name is known in English-speaking academic circles. It was adopted according to English transliteration rules, since Yarbus' works were translated into English. 


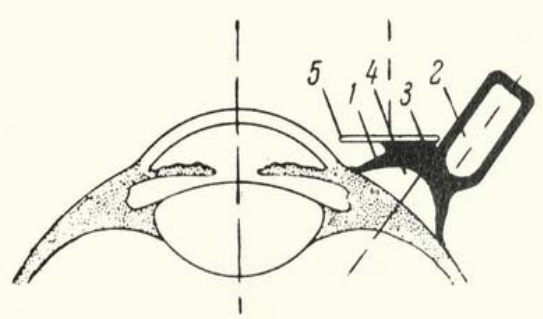

Picture 1. The suction device or "cap" (A.L. Yarbus 1967).

Light reflected from the mirror recorded eye movement on photographic paper. The head of the test subject was immobilised in a metal frame and during the experiment he had to keep biting a special plastic form which was attached to the metal frame and which constituted a cast of the test subjects teeth.

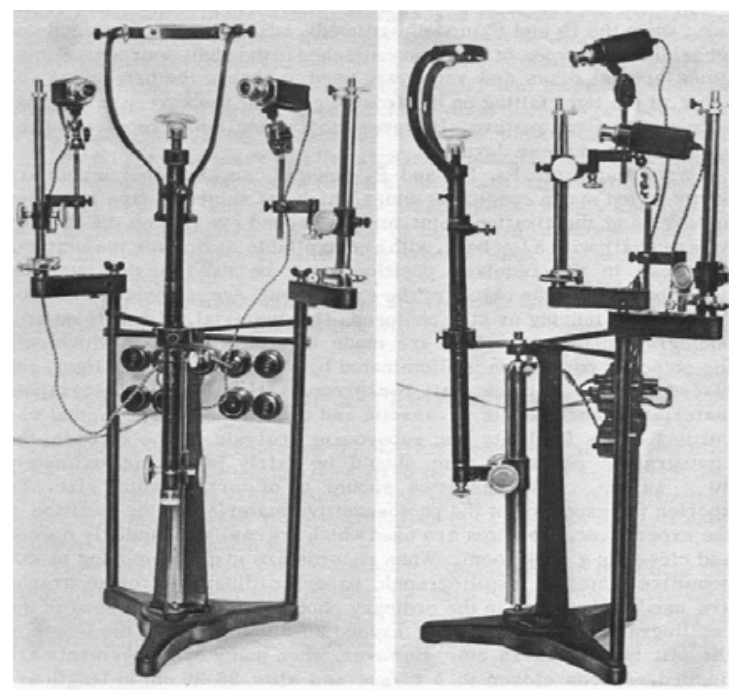

Photograph 5. Yarbus eye tracker (A.L. Yarbus 1967).

This atypical technique was not repeated by other researchers on account of its extreme invasiveness. The experiment could last only a few minutes on account of how extremely inconvenient it was to the subject, whereas data processing took weeks or months (see A.L. Yarbus 1965, 1967).

The highly contentious method allowed A.L. Yarbus to generate interesting results. The results of the experiment showed clearly a dependence of the gazing path on the task the subject was set, i.e. the goal set for the test subject determines the corresponding eye movement, specific perception and regard for specific elements.

A.L. Yarbus revealed also that when watching an image people look not only at the contours but above all at the so-called logic centre (e.g. a person or animal). To the recipients, faces of people mean more than the surrounding figures or conditions. On the other hand, when looking at a portrait, recipients focus mostly on the eyes, 
mouth and nose:

Граница и контур важны для появления зрительного образа, однако когда образ возник и видится непрерывно, у наблюдателя нет необходимости специально интересоваться границами и контурами. Граница и контур всего лишь элементы, из которых наряду с другими, не менее важными элементами складывается наше восприятие и узнавание предмета. Совершенно очевидно, что контур предмета будет привлекать внимание наблюдателя, если в самой форме контура заключены важные и нужные сведения (A.L. Yarbus 2002: 412).

This last remark was illustrated by A.L. Yarbus (2002) by means of the example of a sculpture representing Nefertiti, where the viewers whole attention during the experiment focused on the profile, the contour of the sculpture, as well as on its eyes:

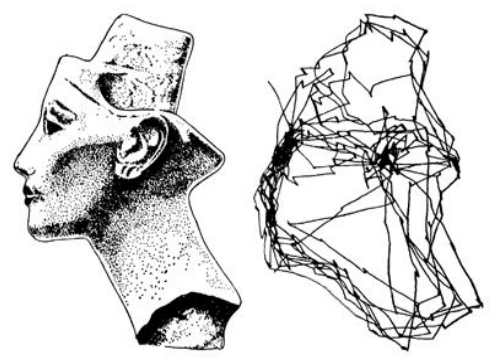

Picture 1. Eye movement depiction for two-minute observation of Nefertiti sculpture (A.L. Yarbus 2002: 412).

Other researchers used special contact lenses fitted with coils; these lenses used the principle of electromagnetic induction: wires attached to the lens registered changes of power induced in the coils under the influences of eye movements in the electromagnetic field generated around the head (quoted from J. Grobelny et al. 2006). However, this method had one major disadvantage: data obtained in such a study could be accessed only after lengthy processing and the results were not visible on an ongoing basis.

The third phase of eye tracking research dates back to the mid-1970s. It coincided with two phenomena referring to:

- psychology, i.e. the establishment of a theoretical and methodological basis for cognitive psychology;

\footnotetext{
${ }^{5}$ The borders and contours are important for the emergence of a complete picture or image, and yet once the image appears and it stays in sight, the observer no longer has to take special interest in the borders and contours. These borders and contours are just some of the elements which, alike others, no less important elements, affect our perception and recognition of the object. It is clear that the outline of an object will attract the observer's attention if the same form of contours indicates an important and necessary information (A.L. Yarbus 2002: 412, own translation).
} 
- technology - i.e. the start of the use of computer and television technology and electronic techniques of detecting the eye and locating it.

This has influenced the character of the third phase of eye tracking research, during which (1) researchers turned more towards the dependence between the perception and mental processes transpiring at the same time in brain and (2) the use of the boom of eye tracking technology. The described stage coincided with the development of linguistic theories on language, language acquisition, text and language properties, language processing, translation etc. This, in turn, had an impact on stretching the range of eye tracking research onto linguistics, to cover among others text perception.

The 1960s saw the creation of the first eye tracking device resembling modern day equipment. It was made for the U.S. Air Force (J. Merchant 1966, 1969; J. Merchant et al. 1974). This device was called the "oculometer".
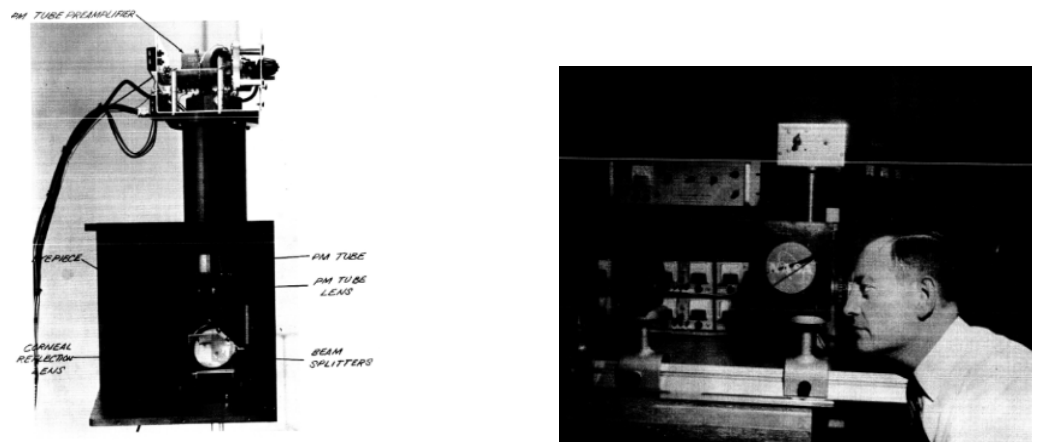

Photograph 6 and 7. Honeywell oculometer (J. Merchant 1966).
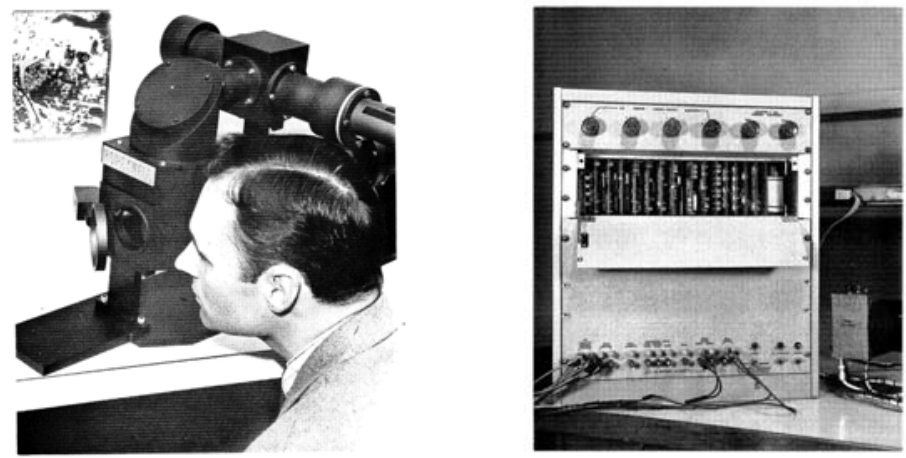

Photograph 8. Improved oculometer devised by J. Merchant.

On the left side - optomechanical unit, on the right-electronics unit (J. Merchant, 1969: 12-13).

Thanks to computer algorithms the iris was recognised on a video screen and its geometrical centre was then determined, as well as the direction in which the tested 
person was looking. This technology resembles modern-day computer-based eye trackers. Meanwhile, in medicine researchers still sometimes use devices based on electromagnetic induction or electrooculographic technology (quoted from: J. Grobelny et al. 2006).

The mobile eye tracker was actually devised simultaneously by two army research teams. The first, as mentioned above, had been commissioned by U.S. Air Force and was produced by Honeywell Corporation, while the other was created for the U.S. Army by EG\&G Corporation. The two eye tracker models relieved the strain of the test subjects; moreover, they became a landmark of eye tracking technology, as they allowed for an automatic analysis of eye tracking data and a faster processing during while the experiment went on (see R.H. Lambert/ R.A. Monty/ R.J. Hall 1974, R.A. Monty 1975; J. Anliker 1976).

Important publications released in that time were based on the development of cognitive psychology and assumed results regarding that field as their starting point. Their authors attempted to develop theoretical models covering the correlation of fixations with particular cognitive processes (i.a.: M.A. Just/ P.A. Carpenter 1976a, 1976b, 1980, works by K. Rayner, i.a.: K. Rayner 1977, 1981, 1983, 1989, also group papers K. Rayner et al. 1989, 1976, 1986 etc., R.A. Monty/ J.W. Senders 1976, J.W. Senders/ D.F. Fisher/ R.A. Monty 1978, D.F. Fisher/ R.A. Monty/ J.W. Senders 1981). There have also been significant studies regarding the analysis of results of eye tracking research (i.a.: R. Kliegl/ R.K. Olson 1981, L.F. Scinto/ B.D. Barnette 1986) and also those concerning themselves with visual imaging in relation to the position of the eye (G.W. McConkie/ K. Rayner 1975, K. Rayner 1975b, S.M. Reder 1973).

An extremely interesting study on the matter, and probably also the most comprehensive one so far, summarising the time from the mid-1970s till 1990s of eyetracking research on reading processes, was drafted in 1998, by K. Rayner in his work "Eye Movements in Reading and Information Processing: 20 Years of Research". The summary drafted by K. Rayner refers to the bigger part to research done by himself and his team, although it does also contain references to crucial achievements in eye tracking research on text perception, carried out by other scientists.

The next stage of eye tracking research started in the 1990s. It was triggered by a fast development of eye tracking technology and an equally sudden surge in computer operation and electronic data processing capacities. The devices became more tolerant of head movements of test subjects, so the head no longer had to be immobilised. Furthermore, the latest technological advancements expanded the range of application of eye tracking techniques. Eye tracking analyses were being used in an ever growing number of scientific fields and business sectors. Many companies dealing professionally in eye tracking studies appeared, offering services in the most diverse areas of life.

What is more, as scientific disciplines advanced and financing for research on universities rose (which corresponded to the ability to buy research equipment), eye tracking studies turned more and more into institutional studies, whole groups of 
scientists, research laboratories, work groups at universities, all specialising in eye tracking, were established. This, in turn, resulted in a sudden spike in the number of various publications, which also contributed to further dissemination of the issue at hand and it sparked more interest in the matter. For instance, Danish firm iMotions, which creates eye tracking and biometric software, has carried out studies using the Internet search instrument Google Scholar, noting how the number of articles with the key work "eye tracking" increased since the $1970 \mathrm{~s}^{6}$ :

\begin{tabular}{|l|l|}
\hline 1970-74: & 310 \\
\hline 1975-79: & 487 \\
\hline $1980-84:$ & 633 \\
\hline $1985-89:$ & 829 \\
\hline $1990-94:$ & 1320 \\
\hline $1995-99:$ & 2540 \\
\hline $2000-04:$ & 7060 \\
\hline $2005-09:$ & 15000 \\
\hline $2010-14:$ & 21600 (projected result) \\
\hline
\end{tabular}

Chart 1. Data on number of articles on eye tracking published in the past decades ${ }^{7}$.

We can bring these results up-to-date and check the number of the articles published online with the key term "eye tracking". Over the last years, the amount of such articles increased dramatically: $2018^{8}-268000$ (in Google Scholar).

Looking at the data one will notice immediately how abruptly interest in eye tracking research soared and, consequently, how the application of the eye tracking methodology widened. In the 1950 s-70s eye tracking was most popular in aviation and aerospace medicine, when researchers examined the response of people in extreme conditions triggered in flight simulations. Also scholars of neurology and psychology took a keen, unwavering interest in eye tracking, as they examined visual perception when reading, experiencing aesthetic sensations (e.g. looking at works of art) and also in studies on processes of concentration. With the time new disciplines were added to the aforementioned research fields where eye tracking studies were continued; these disciplines emerged as a result of consumer needs, commercial market requirements and following the development of technology and various socio-economic phenomena. During the last decade finally researchers from the field of arts and humanities have begun to implement eye tracking equipment in their studies expanding research possibilities, as well as cognitive boundaries. At present the range of application of eye tracking is significantly broader, which, however, goes beyond the subject of this article.

\footnotetext{
${ }^{6}$ The firm iMotions has mostly analysed English publications, the search term was thus the English phrase eye tracking, spelled without a hyphen.

${ }^{7}$ Source: http://imotionsglobal.com/blog/exponential-growth-in-academic-eye-trackingpapers-over-the-last-40-years/ - accessed: 18.03.2014.

${ }^{8}$ Accessed: 19.11.2018.
} 


\section{References}

Ahrens, A. (1891), Die Bewegung der Augen beim Schreiben. Rostock.

Anliker, J. (1976), Eye Movements: On-line Measurement, Analysis, and Control. In: R.S. Monty/ J.W. Senders (eds.), Eye Movements and Psychological Processes. Hillsdale, 185-199.

Bente, G. (2005), Erfassung und Analyse des Blickverhaltens. In: R. Mangold/ P. Vorderer/ G. Bente (eds.), Lehrbuch der Medienpsychologie. Göttingen, 297324.

Buswell, G.T. (1935), How People Look at Pictures. Chicago.

Buswell, G.T. (1937), How Adults Read. Chicago.

Delabarre, E.B. (1898), A Method of Recording Eye-movements. In: "Psychological Review" 8, 572-74.

Diefendor, A.R./ R. Dodge (1908), An Experimental Study of the Ocular Reactions of the Insane from Photographic Records. In: "Brain" 31, 451-489.

Dodge, R./ T.S. Cline (1901), The Angle Velocity of Eye Movements. In: "Psychological Review" 8, 145-157.

Fitts, P.M./ R.E. Jones/ J.L. Milton (1950), Eye Movements of Aircraft Pilots during Instrument-landing Approaches. In: "Aeronautical Engineering Review" 9 (2), 24-29.

Gollücke, V. (2009), Eye-Tracking - Grundlagen, Technologien und Anwendungsgebiete, Studienarbeit. Grin Verlag.

Grobelny, J./ K. Jach/ M. Kuliński/ R. Michalski (2006), Śledzenie wzroku w badaniach jakości użytkowej oprogramowania. Historia $i$ mierniki. (URL https://repin.pjwstk.edu.pl/xmlui/bitstream/handle/186319/166/Kansei\%202006 Grobelny.pdf?sequence=1).

Hartridge, H./ L.C. Thompson (1948), Methods of Investigating Eye Movements. In: "British Journal of Ophthalmology" 32, 581-591.

Huey, E.B. (1898), Preliminary Experiments in the Physiology and Psychology of Reading. In: "American Journal of Psychology" 9, 575-586.

Huey, E.B. (1900), On the Psychology and Physiology of Reading. Part I. In: "American Journal of Psychology" 11 (3), 283-302.

Huey, E.B. (1901), On the Psychology and Physiology of Reading. Part II. In: “American Journal of Psychology" 12 (3), 292-312.

Jacob, R.J.K./ K.S. Karn (2003), Eye Tracking in Human-Computer Interaction and Usability Research: Ready to Deliver the Promises. In: J. Hyönä/ R. Radach/ H. Deubel (eds.), The Mind's Eye: Cognitive and Applied Aspects of Eye Movement Research. Amsterdam, 573-605.

Javal, L.É. (1878), Essai sur la physiologie de la lecture. In: "Annales d'Oculistique", 80, 240-274.

Javal, L.É. (1879), Essai sur la physiologie de la lecture. In: “Annales d'Oculistique" $82,242-253$.

Javal, L.É. (1905), Physiologie de la lecture et de l'écriture. Paris: Alcan.

Judd, C.H./ C.N. McAllister/ W.M. Steel (1905), General introduction to a series of studies of eye movements by means of kinetoscopic photographs. In: J.M. Bald- 
win/ H.C. Warren/ C.H. Judd (eds.), Psychological Review, Monograph Supplements. Baltimore, 1-16.

Just, M.A./ P.A. Carpenter (1976a), Eye Fixations and Cognitive Processes. In: "Cognitive Psychology" 8, 441-480.

Just, M.A./ P.A. Carpenter (1976b), The Role of Eye-fixation Research in Cognitive Psychology. In: "Behavior Research Methods \& Instrumentation" 8, 139-143.

Just, M.A./ P.A. Carpenter (1980), A Theory of Reading: From Eye Fixations to Comprehension. In: "Psychological Review" 87 (4), 329-354.

Kliegl, R./ R.K. Olson (1981), Reduction and Calibration of Eye Movement Data. In: "Behavior Research Methods and Instrumentation" 13, 107-111.

Landolt, E. (1891), Nouvelle recherches sur la physiologie des mouvements des yeux. In: "Archives d'Ophthalmologie" 11, 385-395.

Mackworth, J.F./ N.H. Mackworth (1958), Eye Fixations Recorded on Changing Visual Scenes by Television Eye-marker. In: "Journal of Optical Society of America" 52, 713-716.

Mackworth, N.H./ E.L. Thomas (1962), Head-mounted Eye-marker Camera. In: "Journal of the Optical Society of America" 52, 713-716.

McConkie, G.W./ K. Rayner (1975), The Span of the Effective Stimulus during a Fixation in Reading. In: "Perception \& Psychophysics" 17, 578-586.

Merchant J. (1966), Interim Technical Report. Oculometer. Contract No. NASW1159. February 25, 1965 - December 25, 1965. Boston.

Merchant, J./ R. Morrissette/ J.L. Porterfield (1974), Remote Measurement of Eye Direction Allowing Subject Motion over One Cubic Foot of Space. In: "IEEE Transactions on Biomedical Engineering" 21 (4), 309-317.

Monty, R.A. (1975), An Advanced Eye-movement Measuring and Recording System. In: "American Psychologist" 30, 331-335.

Monty, R.A./ J.W. Senders (eds.) (1976), Eye Movements and Psychological Processes, Hillsdale.

Płużyczka, M. (2015), Tłumaczenie a vista. Rozważania teoretyczne i badania eyetrackingowe. Warszawa.

Rählmann, E. (1878), Über den Nystagmus und seine Ätiologie. In: "Archiv für Ophthalmologie" 24, 237-242.

Rayner, K. (1975), The Perceptual Span and Peripheral Cues in Reading. In: "Cognitive Psychology" 7, 65-81.

Rayner, K. (1977), Visual Attention in Reading: Eye Movements Reflect Cognitive Processes. In: "Memory \& Cognition" 5, 443-448.

Rayner, K. (1983), Eye Movements in Reading: Perceptual and Language Processes. San Diego.

Rayner, K. (1998), Eye Movements in Reading and Information Processing: 20 Years of Research. In: "Psychological Bulletin" 124 (3), 372-422.

Rayner, K./ G.W. McConkie (1976), What Guides a Reader's Eye Movements?. In: "Vision Research" 16, 829-837.

Rayner, K./ G.W. McConkie/ D. Zola (1980), Integrating Information across Eye Movements. In: “Cognitive Psychology” 12, 206-226. 
Reder, S.M. (1973), On-line Monitoring of Eye Position Signals in Contingent and Noncontingent Paradigms. In: "Behavior Research Methods and Instrumentation" 5, 218-228.

Scinto, L.F./ B.D. Barnette (1986), An Algorithm for Determining Clusters, Pairs or Singletons in Eye-movement Scan-path Records. In: "Behavior Research Methods, Instruments \& Computers" 18, 41-44.

Shackel, B. (1960), Note on Mobile Eye Viewpoint Recording. In: "Journal of the Optical Society of America" 59, 763-768.

Stone, L.G. (1941), Reading Reactions for Varied Types of Subject Matter: An Analytical Study of the Eye-movements of College Freshmen. In: "Journal of Experimental Education" 10 (1), 64-77.

Tinker, M.A. (1946), A Study of Eye Movements in Reading. In: "Psychological Bulletin" 43 (2), 93-120.

Tinker, M.A. (1958), Recent Studies of Eye Movements in Reading. In: "Psychological Bulletin" 55 (4), 215-231.

Tscherning, M.H.E. (1898), Optique physiologique. Paris: Carré and Naud.

Wade, N.J./ B.W. Tatler (2009), Did Javal Measure Eye Movements during Reading?, (w:) "Journal of Eye Movement Research" 2(5), 1-7.

Walker, R.Y. (1933), The Eye-movements of Good Readers. In: "Psychological Monographs" 44 (3), 95-117.

Yarbus, A.L. (1967), Eye Movements and Vision. New York. 